\title{
Transverse Fracture of the Stapes Anterior Crus Caused by the Blast Pressure from a Land Mine Explosion
}

\author{
Seok Min Hong, Jun Ho Lee, Chan Hum Park, and Hyung-Jong Kim \\ Department of Otorhinolaryngology-Head and Neck Surgery, School of Medicine, Hallym University, Chuncheon, Korea
}

Received February 25, 2014

Revised May 2, 2014

Accepted May 15, 2014

Address for correspondence

Jun Ho Lee, MD, PhD

Department of Otorhinolaryngology-

Head and Neck Surgery,

School of Medicine,

Hallym University,77 Sakju-ro,

Chuncheon 200-704, Korea

Tel +82-33-240-5181

Fax $+82-33-241-2909$

E-mailzzoonox@nate.com
Stapes fractures without other ossicle problems are rare and ossicle problems due to explosion pressure are also rare. We describe a very rare case of stapes anterior crural fracture resulting from a land mine explosion. As this case suggests, a close examination of the ossicles is necessary during an exploration tympanotomy.

Korean J Audiol 2014;18(3):137-140

KEY WORDS: Stapes · Bone fractures · Bombs · Explosions.

\section{Introduction}

Hearing impairment frequently follows head trauma. The hearing impairment can be sensorineural, conductive, or a mixed hearing loss according to the area affected by the trauma. When head trauma patients suffer acute conductive hearing loss, the most common etiology except traumatic drum perforation is an intratympanic hemorrhage due to temporal bone fracture. If the conductive hearing loss has not resolved several months later, ossicular disruption due to head trauma is suggested. $^{1-3)}$

The most common forms of traumatic ossicular disruption are incus-stapes or malleus-incus dislocation. Multiple problems involving parts of the ossicular complex are more frequent than single problem.

Almost all ossicular problems caused by trauma result from direct pressure on the temporal area or the effects of a temporal bone fracture. Consequently, disruption between the incus and stapes or malleus and incus is more common than ossicular fractures because these portions are the most vulnerable

This is an Open Access article distributed under the terms of the Creative Commons Attribution Non-Commercial License (http://creativecommons. org/licenses/by-nc/3.0/) which permits unrestricted non-commercial use, distribution, and reproduction in any medium, provided the original work is properly cited. portions of the ossicles. In our case, the ossicular pathology was very unusual because an anterior crus fracture occurred, while the remaining ossicles were normal.

Stapes fractures without other ossicle problems are rare and ossicle problems due to explosion pressure are also rare. ${ }^{4,5)} \mathrm{We}$ report a very rare transverse fracture of the stapes anterior crus caused by the blast pressure from a land mine explosion and discuss the pathophysiology with a literature review.

\section{Case Report}

A 40-year-old man was admitted to our hospital with a lumbar vertebral fracture. A land mine had exploded near where he was working. On admission, he had hearing loss in both ears. The physical examination revealed perforations of both tympanic membranes (Fig. 1A, B). He had no history of otalgia, otorrhea, vertigo, or ear surgery. Audiometry showed moderate conductive hearing loss bilaterally (Fig. 2A). The air-bone gap was wider on the right side. Temporal bone computed tomography detected no abnormal findings on the right, but revealed partial soft tissue haziness of the left mastoid and mesotympanum (Fig. 3).

With the patient under local anesthesia, underlay tympanoplasties were performed bilaterally. After tympanomeatal flaps 

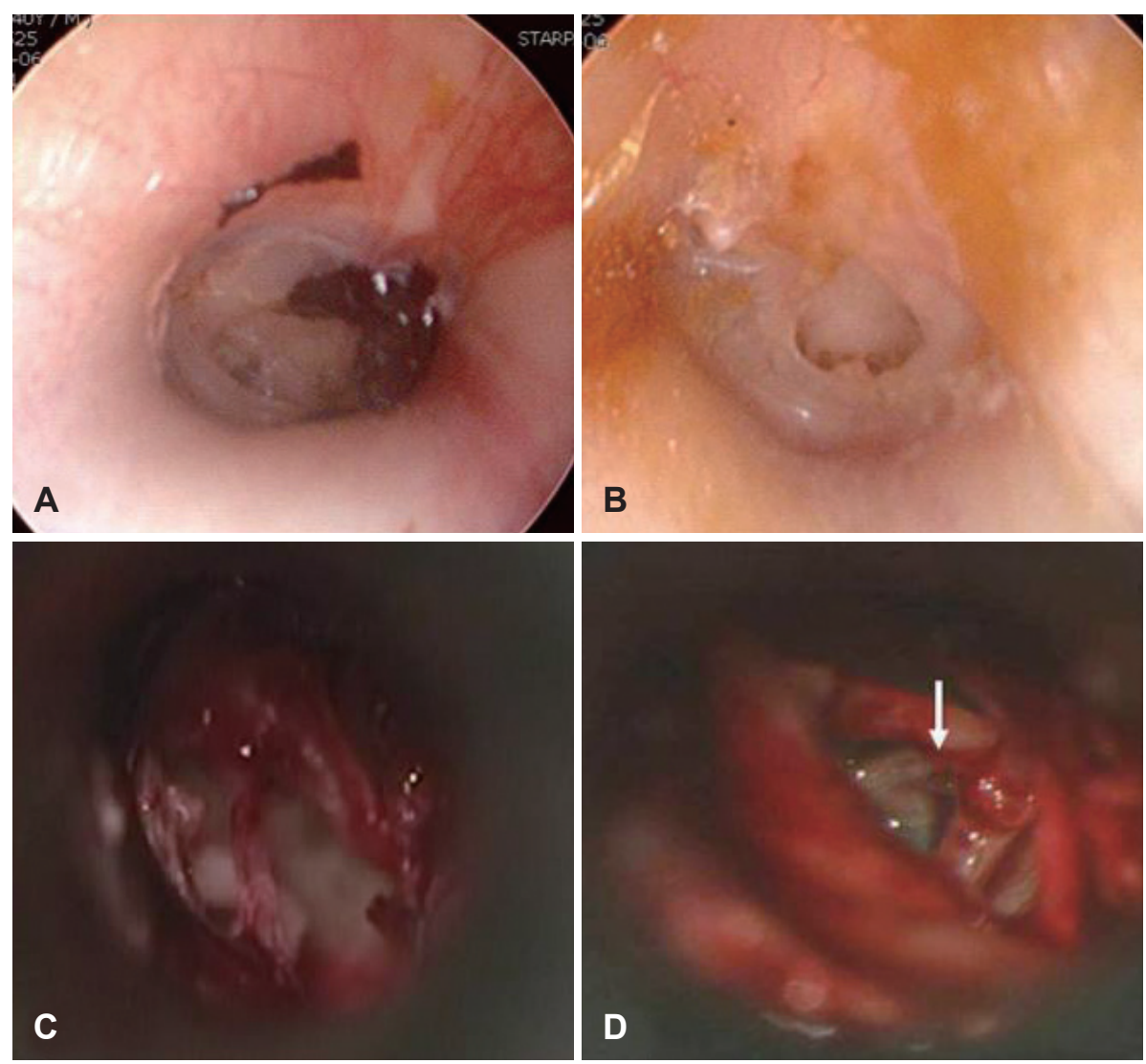

Fig. 1. A, B: Preoperatively, moderate central drum perforations were seen bilaterally. C: On the right side during the primary tympanoplasty, after a tympanomeatal flap was elevated, the mobilities of the malleoincudal and incudostapedial joints were normal. Drum grafting was successful. D: At the right-side revision exploration tympanotomy, a fracture of the anterior crus was noted (white arrow).

were elevated, normal mobility of the ossicles was seen (Fig. 1C). Drum grafting was successful on both sides.

Follow-up pure tone audiometry was performed 12 weeks postoperatively. The air-bone gap had improved on the left, while minimal change occurred on the right (Fig. 2B). So we planned a revision exploratory tympanotomy on the right under local anesthesia. After tympanomeatal flaps were elevated, ossicular mobility was checked. When malleus handle was manipulated, incudo-stapedial joint was moved. A mild mucosal web around the ossicles was removed. After repositioning the elevated tympanomeatal flap on the external acoustic meatus, we checked the subjective hearing gain using the whispered voice test during the operation. However, no hearing improvement was evident, and so we re-examined the ossicles. We focused stapes because other ossicles were normal condition. At this time, we found a fracture line through the anterior crus (Fig. 1D). Moving the incus long process using an angled pick did not affect the footplate mobility. Therefore, we tried removing the stapes suprastructure to insert a total ossicular replacement prosthesis (TORP), but failed because of normal footplate mobility. Consequently, the TORP was inserted through the under-portion of the suprastructure without removing the suprastructure. After repositioning the tympanomeatal flap, we confirmed the hearing improvement subjec- tively. Seventeen weeks after the revision exploratory tympanotomy, the air-bone gap on the right side was minimal (Fig. 2C).

\section{Discussion}

Strong air pressure on the tympanic membrane can cause drum perforation. Commonly, we see traumatic drum perforation with a slap to the head, but the air pressure during a slap is insufficient to induce ossicular fracture.

When people are close to an exploding bomb, 27.6-62\% of them experience perforated eardrums. ${ }^{6-8)}$ Although South and North Korea fought each other during the Korean War from 1950 to 1953, an armistice since then has been imposed. Consequently, although the risk of the explosion of a land mine buried near the cease-fire line is low, the high air pressure resulting from an exploding mine may be sufficient to induce ossicular problems via drum perforation.

The anterior crus is hidden behind the stapedial tendon and incus long process when a transmeatal approach is used for surgery. Consequently, checking the condition of the anterior crus during an exploratory tympanotomy is difficult. In standard practice, the movement of the stapedial tendon or stapes outline is checked when we test the mobility of the incudostapedial joint or footplate. In our case, we missed the patient's 
main problem (the anterior crus fracture) because the mobility of the stapedial head and tendon was normal during the first tympanoplasty and the first attempt during the revision exploration tympanotomy.

No hearing improvement was observed after the first operation on the right side. The drum perforation had been correct- ed, another problem about hearing conduction had to be responsible. This afforded proof of the effect of an anterior crus fracture on hearing conduction. The stapes crura are very thin structures; typically, the anterior crus is $0.219 \mathrm{~mm}$ thick and the posterior crus $0.113 \mathrm{~mm}$. ${ }^{9}$ So when the intact crus is disconnected from the other crus, mechanical sound energy is no

Fig. 2. A: Preoperative pure tone audiometry shows a wider air-bone gap on the right side. B: Follow-up pure tone audiometry 12 weeks after the first operation shows an improved air-bone gap on the left, but minimal change on the right. C: Follow-up pure tone audiometry 17 weeks after the revision exploration tympanotomy and ossiculoplasty shows that the air-bone gap on the right was minimal.
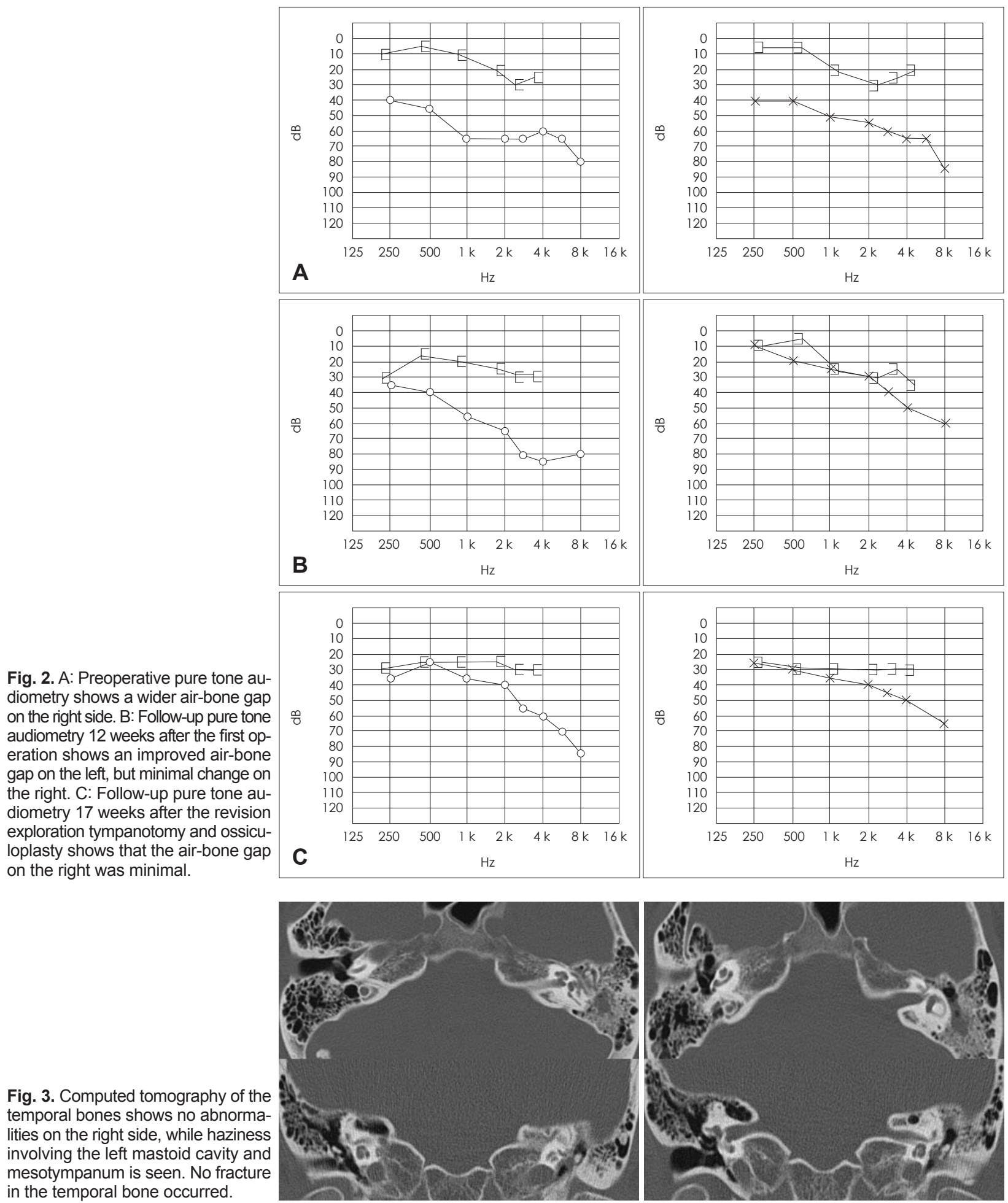


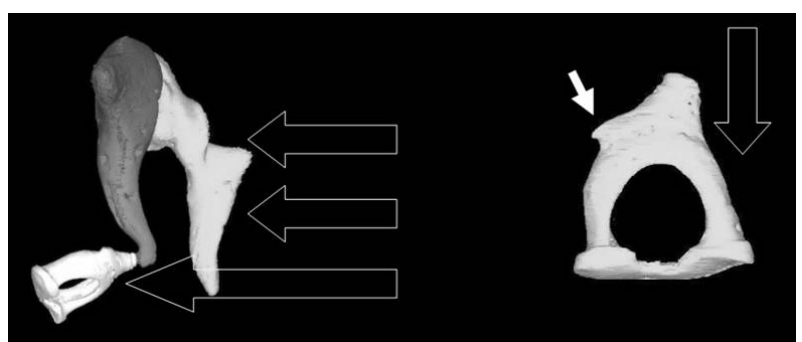

Fig. 4. Illustration of the pathophysiological mechanism. The ossicles complex was subjected to high air pressure through the perforated drum. The pressure was concentrated on the thinnest, most vulnerable portion, the stapes crura. As the posterior crus was supported by the stapedial tendon (white arrow), the anterior crus sustained a wedge-type fracture. Empty large arrows show the direction of the mechanical pressure.

longer conducted. Simmons and Parkins ${ }^{10)}$ refuted the hypothesis that a fracture of one (the anterior) stapedial crus will significantly alter ossicular sound transmission in an experimental animal model. However, the three-dimensional anatomy differs between humans and rats. ${ }^{11)}$ Consequently, the contribution of the human anterior crus to hearing transmission differs from that in rats or other animals.

We postulated that the pathophysiological mechanism of the injury was an effect of high air pressure in contact with the ear drum damaging the ossicles directly through the drum. The protective effect of the tensor tympani and stapedial tendon was negated by the very high air pressure and the rapidity of the explosion. Consequently, the air pressure acted on the ossicles, including the stapes, as a single body. Both crura are very vulnerable because of their very thin architecture. Since the posterior crus was hidden behind the posterior bony annulus and was supported by the stapedial tendon, the mechanical energy might be focused on the anterior crus, which fractured although the anterior crus is thicker than the posterior crus (Fig. 4). In appearance, the fracture was like a compression wedge fracture of a vertebral body due to pressure induced vertically because the vertebral body is supported by the back muscles and tendons posteriorly. Vertebral spine fractures are classified into compression fractures, burst fractures, seat-belt type fractures, and fracture dislocations. ${ }^{12)}$ Of these, compression fractures have a pattern similar to the fracture in our case. A compression fracture involves failure of the anterior column only, while the middle and posterior columns remain intact. In contrast, the other types of fracture all involve failure of all three columns. Cadaveric studies have revealed that when specimens are loaded in neutral alignment, a vertebral compression-type deformity often results, and the ligament complex of the posterior element is important at the limit of flexion. ${ }^{13,14)}$

Few studies have reported on trauma to the stapes. ${ }^{5,15)}$ The stapes is a very small, vulnerable structure, so the effects of trauma are variable. Our case was unusual because it was an isolated anterior crus fracture without damage to the other ossicles. Our case was similar to two cases in Yetiser's report, although Yetiser, et al. ${ }^{5)}$ did not propose a pathophysiological mechanism. As this case suggests, a close examination of the ossicles is necessary during an exploratory tympanotomy.

\section{REFERENCES}

1) Tos M. Prognosis of hearing loss in temporal bone fractures. J Laryngol Otol 1971;85:1147-59.

2) Does IE, Bottema T. Posttraumatic conductive hearing loss. Arch Otolaryngol 1965;82:331-9.

3) Hammond V. Conductive deafness following head injury. J Laryngol Otol 1964;78:837-48.

4) Hough JV, Stuart WD. Middle ear injuries in skull trauma. Laryngoscope 1968;78:899-937.

5) Yetiser S, Hidir Y, Birkent H, Satar B, Durmaz A. Traumatic ossicular dislocations: etiology and management. Am J Otolaryngol 2008; 29:31-6.

6) de Ceballos JP, Turégano-Fuentes F, Perez-Diaz D, Sanz-Sanchez M, Martin-Llorente C, Guerrero-Sanz JE. 11 March 2004: The terrorist bomb explosions in Madrid, Spain--an analysis of the logistics, injuries sustained and clinical management of casualties treated at the closest hospital. Crit Care 2005;9:104-11.

7) Persaud R, Hajioff D, Wareing M, Chevretton E. Otological trauma resulting from the Soho Nail Bomb in London, April 1999. Clin Otolaryngol Allied Sci 2003;28:203-6.

8) Mrena R, Pääkkönen R, Bäck L, Pirvola U, Ylikoski J. Otologic consequences of blast exposure: a Finnish case study of a shopping mall bomb explosion. Acta Otolaryngol 2004;124:946-52.

9) Park K, Moon SK, Lee JH, Won YY, Baek MH. Study on the three dimensional structure of the human ossicle using micro CT. Korean J Otolaryngol-Head Neck Surg 2003;46:276-81.

10) Simmons MJ, Parkins CW. Effects of stapedial arch fractures on conductive hearing loss and stapedial reflexes. Ear Hear 1996;17:559-63.

11) Lee JH, Park K, Kang TC, Choung YH. Three-dimensional anatomy of the temporal bone in normal mice. Anat Histol Embryol 2009;38: 311-5.

12) Denis F. Spinal instability as defined by the three-column spine concept in acute spinal trauma. Clin Orthop Relat Res 1984:65-76

13) Langrana NA, Harten RD RD, Lin DC, Reiter MF, Lee CK. Acute thoracolumbar burst fractures: a new view of loading mechanisms. Spine (Phila Pa 1976) 2002;27:498-508.

14) Adams MA, Hutton WC, Stott JR. The resistance to flexion of the lumbar intervertebral joint. Spine (Phila Pa 1976) 1980;5:245-53.

15) Ederies A, Yuen HW, Chen JM, Aviv RI, Symons SP. Traumatic stapes fracture with rotation and subluxation into the vestibule and pneumolabyrinth. Laryngoscope 2009;119:1195-7. 